\title{
Correlation between the femoral trochlear line - epicondylar line angle and intercondylar notch width index in an Iranian population
}

\author{
Sasan Shahsavaripour, Mohammad Barbarestani, Gholamreza Hassanzadeh, Tayebeh Rastegar \\ Department of Anatomy, School of Medicine, Tebran University of Medical Sciences, Tebran, Iran
}

\begin{abstract}
Objectives: Distal femur anthropometric indices are the main parameters for the design of knee implants. However, there are several variations concerning the anatomy and congruence of the distal femur in different populations. The purpose of this study was to identify anthropometric data on the distal femur and investigate the correlation between the trochlear line - epicondylar line angle and intercondylar notch width index in an Iranian population.

Methods: Distal femur measurements were performed in 158 knees on bony specimens and 187 MRIs from an Iranian population. Intercondylar width, intercondylar notch width, and trochlear line - epicondylar line angle were measured and intercondylar notch width index was calculated.

Results: In bony specimens, the trochlear line - epicondylar line angle was measured as $7.38^{\circ}$ and intercondylar notch width as $19.36 \mathrm{~mm}$. In MRI images, the trochlear line - epicondylar line angle was measured as $6.07^{\circ}$ and notch width index as 0.276 $\mathrm{mm}$. Linear regression analysis showed a significant relationship between the trochlear line - epicondylar line angle and notch width index $(p<0.05)$.

Conclusion: The results of this study provide fundamental data for the design of knee prostheses suitable for the Iranian population.
\end{abstract}

Keywords: anthropology; notch width index; total knee arthroplasty; trochlea epicondylar angle

Anatomy 2017;11(2):87-92 @2017 Turkish Society of Anatomy and Clinical Anatomy (TSACA)

\section{Introduction}

In total knee arthroplasty (TKA), maximum implant covering on the bone surface minimizes the stress applied to the bone-implant interface. ${ }^{[1]}$ A good shape match between the prosthesis and the resected surface of the knee is reported as an important factor for long term survival of TKA. Most of the available TKA prostheses are designed according to the anthropometric data from American or European populations, which is suspected to be the cause of mismatch of these prostheses in Asian people. $^{[2]}$

Distal femur anthropometric indices are the main parameters in the design of knee implants, and are important determinants for achieving a well-balanced flexionextension gap in a TKA. Several studies studied the distal femur and reported knee morphometric indices for sizing the femoral component of knee prostehesis. ${ }^{[3-9]}$ The notch width index (NWI) and other morphologic parameters of the knee joint are importantin designing knee prostheses. ${ }^{[4]}$ However, most of the studies are reports from North America, ${ }^{[4,5]}$ Europe $^{[6]}$ and Asia. ${ }^{[7-9]}$

Iranic people are an ethnical group among the Asian population. ${ }^{[10]}$ However, the number of previous studies on knee morphometry is limited, there is only one study on CT scans of 150 patients on some measurements from distal femur, namely width of the medial and lateral condyles, anteroposterior length of the lateral condyles, and intercondylar width. ${ }^{[1]}$ Also, there were no studies in the literature investigating anthropological parameters of the bony specimens in the Iranian population. The aim of this study was to to evaluate whether current total knee prostheses are proportionally matching to anatomical pro- 
files of the Iranian knees by measurements from bones and MRI images of the femur.

\section{Materials and Methods}

This cross sectional study was performed on 158 cadaveric knees from the Department of Anatomy, School of Medicine, Tehran University of Medical Sciences, Tehran, Iran, and on 187 patients that underwent MRI on one or both knees between October 2015 and April 2016 in Shariati Hospital, Tehran, Iran with institutional ethic approval. Pertinent demographic and clinical history was obtained from the existing medical charts. Patients with knee deformities or dysplasia, connective tissue or hematologic disorders, fractures involving articular surfaces, prior knee arthroscopy/surgery or osteoarthritis were excluded from the study. ${ }^{[12]}$ The measurements were performed in the frontal plane in MR images, and in the horizontal plane in bone specimens. Therefore, we did not make a comparison between the bone and MRI samples.

According to earlier reports, a measurement of femoral head diameter less than $42.5 \mathrm{~mm}$ indicates a female and a measurement greater than $47.5 \mathrm{~mm}$ indicates a male. A midshaft femoral head circumference measurement less than $81 \mathrm{~mm}$ indicates a female, while measurements above $81 \mathrm{~mm}$ indicates a male. ${ }^{[13,14]}$ Identification of the left and right femur was based on the anatomical position and landmarks. ${ }^{[15]}$ Based on these parameters, bones studied were from 121 males and 37 females. From these, 88 bones were from the right side and $70 \mathrm{frpm}$ the left side. Knee MRIs were from 187 patients (91 males, 96 females) from the Radiology Department of Shariati Hospital, Tehran, Iran. Of these, 99 MRIs were from the right and 88 from the left knee.
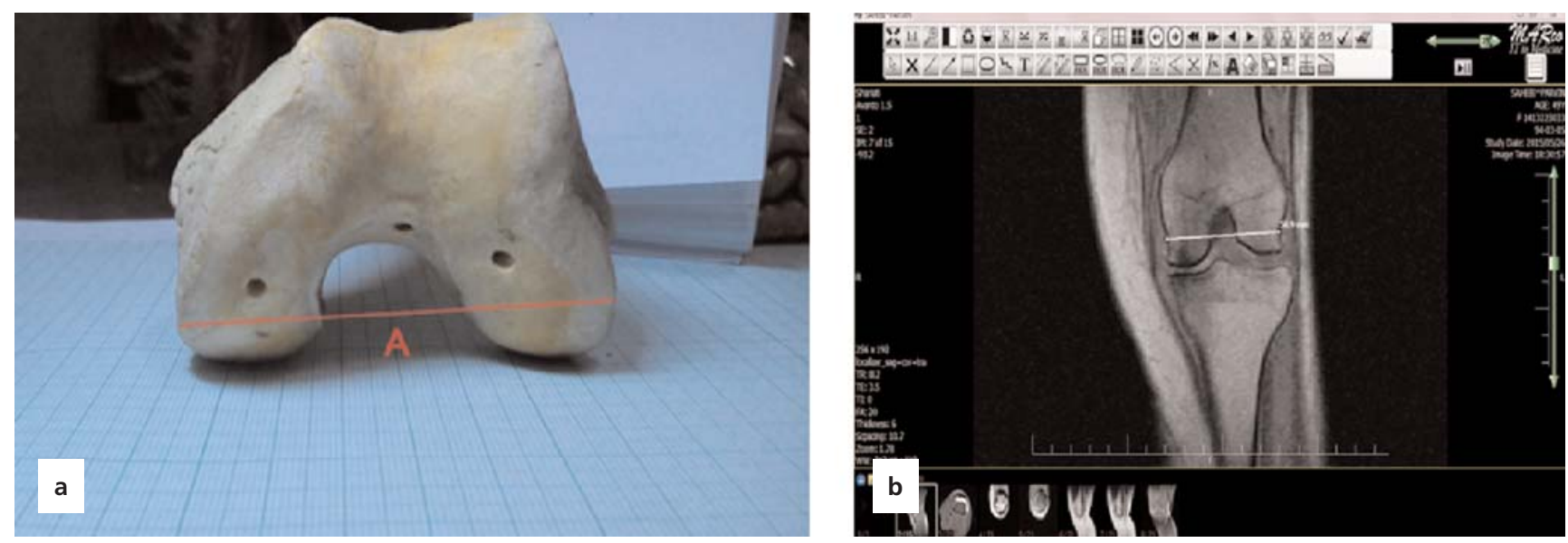

Figure 1. (a) Bicondylar line in distal femur and (b) intercondylar width on MRI image. [Color figure can be viewed in the online issue, which is available at www.anatomy.org.tr] 
ured as the length between the medial projection of the lateral condyle and the lateral projection of the medial condyle of the femur. The ICW was determined by measuring the line passing through the popliteal groove and running parallel to the line drawn between the condylar ends across the most distal aspect of femur. Both measurements were performed on axial images (Figure 3). Employing the criteria of Domzalski et al. ${ }^{[18]}$ a value of 0.27 or more for the NWI was considered as normal, whereas values equal to or below 0.269 were considered as low.

The TEA is between two lines: trochlear line as the line passing through the most anterior points of the trochlea and the epicondylar line as the maximum distance between the internal and external epicondyles. ${ }^{[5,19]}$ The angle between the two lines was measured (Figure 4).

All comparisons between categories were made using the $\mathrm{v} 2$ test. $\mathrm{p} \leq 0.05$ was considered to be statistically significant.

\section{Results}

In bony specimens, the mean ICW was measured as $65.98 \mathrm{~mm}, 61.33 \mathrm{~mm}$ in females and $67.46 \mathrm{~mm}$ in males and females. The NW was $17.9 \mathrm{~mm}$ in females and 19.8 $\mathrm{mm}$ in males, and $19.36 \mathrm{~mm}$ in males and females. The NWI was $0.292 \mathrm{~mm}$ in females, and $0.291 \mathrm{~mm}$ in males, and $0.291 \mathrm{~mm}$ in males and females. The mean TEA line angle was in $7.17^{\circ}$ in females, $7.48^{\circ}$ in males, and $7.38^{\circ}$ in males and females.

In MRI images, the ICW was $63.92 \mathrm{~mm}$ in females, $74.58 \mathrm{~mm}$ in males, and $69.11 \mathrm{~mm}$ in males and females. NWI was $17.93 \mathrm{~mm}$ in females, $19.98 \mathrm{~mm}$ in males, and $18.92 \mathrm{~mm}$ in males and females. In bony specimens, NWI was $0.28 \mathrm{~mm}$ in females, $0.268 \mathrm{~mm}$ in males, and $0.276 \mathrm{~mm}$ in males and females. TEA was $5.76^{\circ}$ in

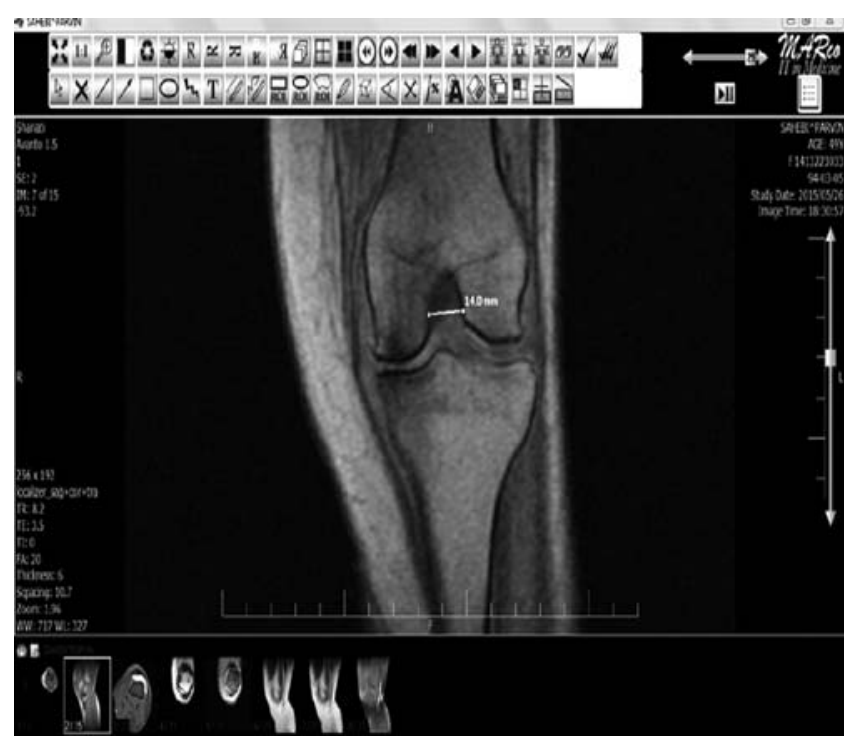

Figure 2. Measurement of notch width (NW) on MRI.

females, $6.48^{\circ}$ in males and $6.07^{\circ}$, in males and females (Table 1).

Linear regression results showed that one degree rise of TEA decreased the NWI 0.002 units. This relationship was statistically significant $(\mathrm{p}<0.05)$. Linear regression analysis for MRI images showed that for one degree rise in TEA, NWI decreased by 0.006 , and this correlation was also statistically significant $(\mathrm{p}<0.05)$ (Figure 5).

\section{Discussion}

Measurements of knee morphometric parameters are important in the construction, design and selection knee prosthesis. The aim of this study was to identify clearly discernible, reliable anthropometric indices of knee that could be used in construction of prosthesis commonly used in TKA. To our knowledge, this is the first study to
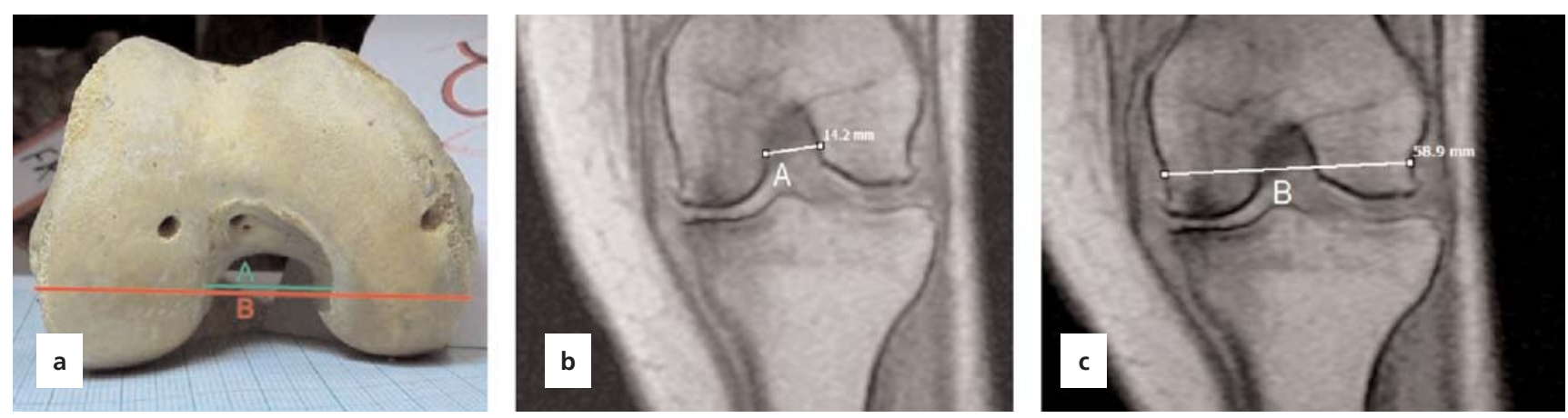

Figure 3. (a-c) Intercondylar notch width $(\mathbf{A})$ and intercondylar width (B) in bony and MRI specimens. [Color figure can be viewed in the online issue, which is available at www.anatomy.org.tr] 


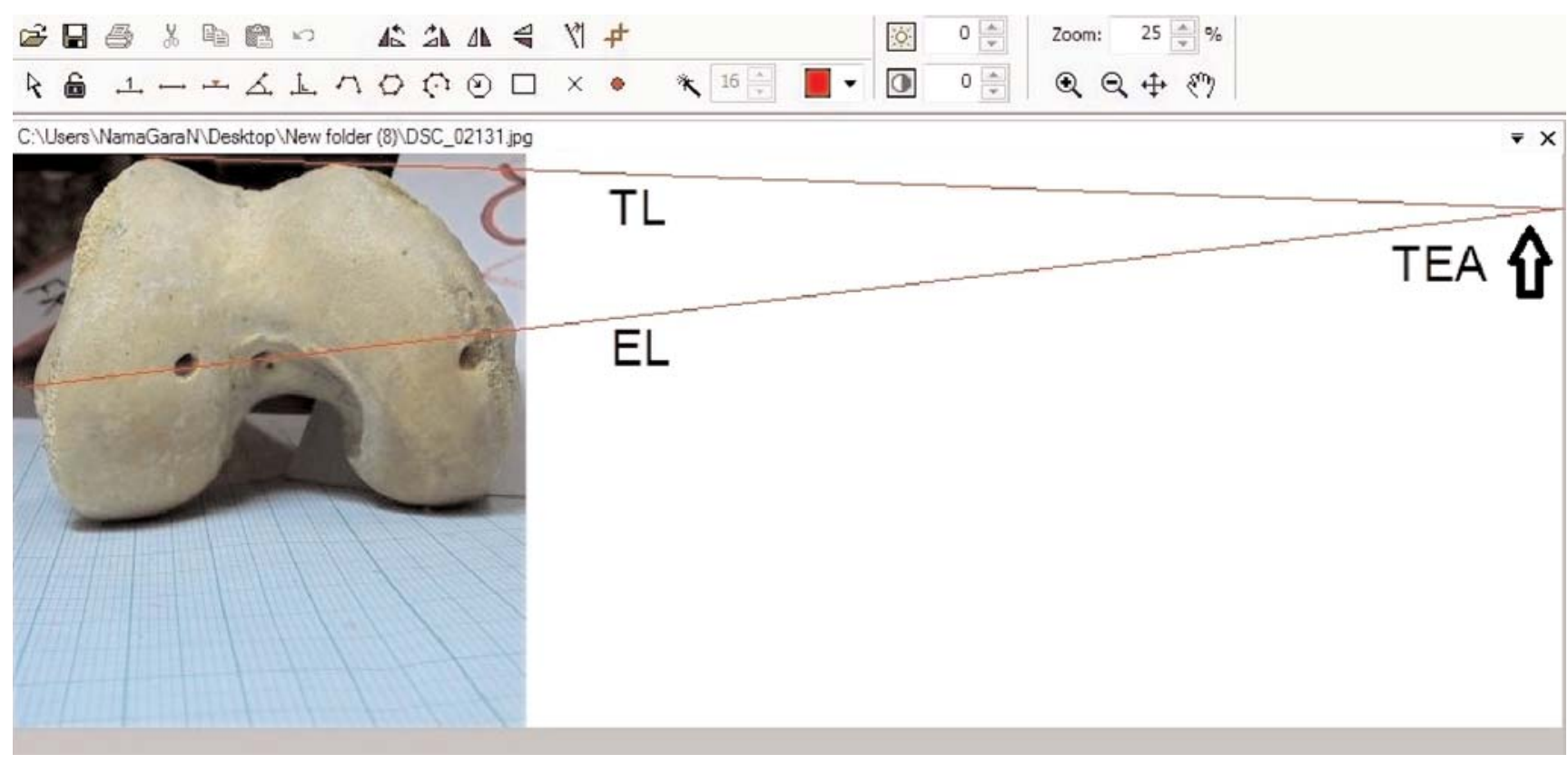

Figure 4. Measurement of TEA using Digimizer free image analysis software (Version 4.0.0; MedCalc Software, Mariakerke, Belgium). Trochlear line $(\mathrm{TL})$ is the line passing from the most anterior point of the trochlea and the epicondylar line (EL) is the maximum distance beween the medial and lateral epicondyles. [Color figure can be viewed in the online issue, which is available at www.anatomy.org.tr]

Table 1

Intercondylar width (ICW), intercondylar notch width (NW), notch width index (NWI) and trochlear line - epicondylar line angle (TEA) in bones and MRI images (mm, Mean $\pm \mathrm{SD})$.

\begin{tabular}{|c|c|c|c|c|c|}
\hline Method & Variable & ICW & NW & NWI & TEA \\
\hline \multirow[t]{4}{*}{ MRI images } & Right (n=99) & $69.21 \pm 6.87$ & $19.06 \pm 2.83$ & $0.276 \pm 0.036$ & $6.10 \pm 1.23$ \\
\hline & Left $(n=88)$ & $69 \pm 6.91$ & $18.73 \pm 3.09$ & $0.272 \pm 0.041$ & $6.20 \pm 1.14$ \\
\hline & Male $(n=91)$ & $74.58 \pm 4.8$ & $19.98 \pm 3.07$ & $0.268 \pm 0.028$ & $6.48 \pm 1.08$ \\
\hline & Female $(n=96)$ & $63.92 \pm 3.85$ & $17.93 \pm 2.46$ & $0.280 \pm 0.035$ & $5.76 \pm 1.05$ \\
\hline \multirow[t]{4}{*}{ Dry bones } & Right $(\mathrm{n}=88)$ & $65.98 \pm 5.35$ & $19.3 \pm 2.76$ & $0.291 \pm 0.028$ & $7.61 \pm 2.22$ \\
\hline & Left $(n=70)$ & $66 \pm 5.98$ & $19.44 \pm 2.56$ & $0.292 \pm 0.028$ & $7.07 \pm 1.8$ \\
\hline & Male $(n=121)$ & $67.44 \pm 5.14$ & $19.80 \pm 2.66$ & $0.291 \pm 0.029$ & $7.48 \pm 2.12$ \\
\hline & Female $(n=37)$ & $61.33 \pm 4.13$ & $17.99 \pm 2.24$ & $0.292 \pm 0.025$ & $7.17 \pm 1.93$ \\
\hline
\end{tabular}
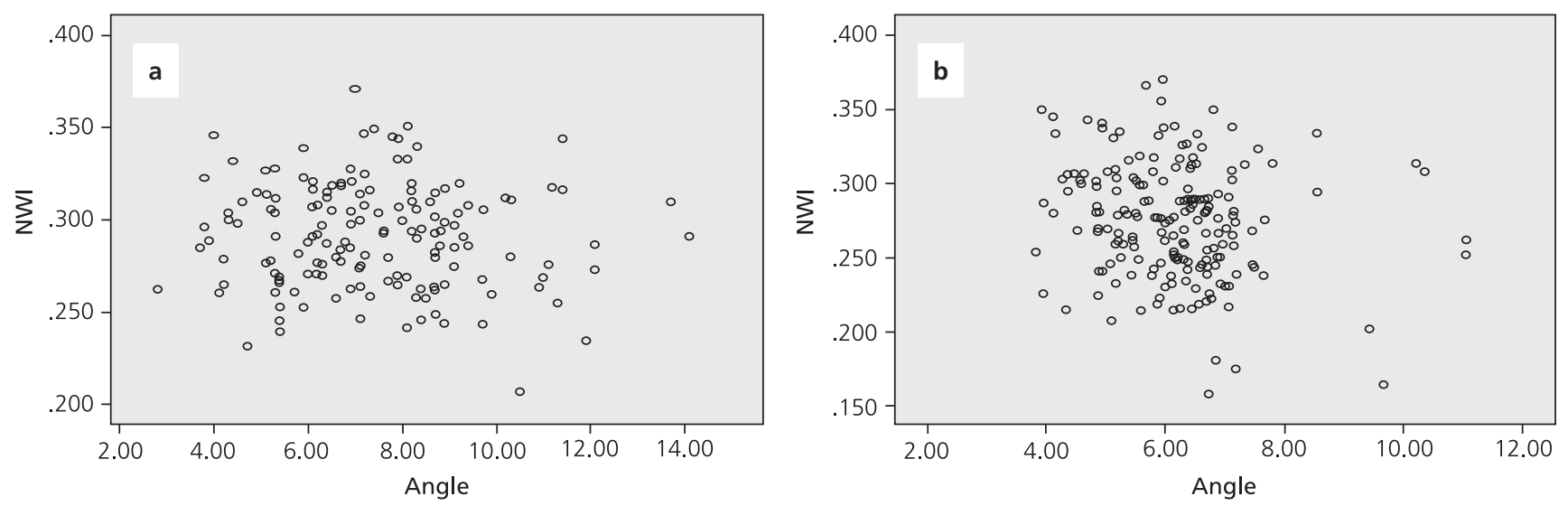

Figure 5. Linear regression of NWI and TEA in (a) bones and (b) MRI images. 
investigate the relationship between NWI and TEA in normal knees using MRI and dissected bones in an Iranian population.

ICW is important in anatomical, clinical, anthropometric and orthopedic parameter, particularly for TKA. According to our results, ICW was $65.9 \mathrm{~mm}(61.3 \mathrm{~mm}$ in females and $67.4 \mathrm{~mm}$ in males) in bony specimens, and $69.1 \mathrm{~mm}$ (63.9 $\mathrm{mm}$ in females and $74.5 \mathrm{~mm}$ in males) in MRI images. This variable was $70.6 \mathrm{~mm}$ in Japanese, $71.2 \mathrm{~mm}$ in Chinese, ${ }^{[20]} 70.2 \mathrm{~mm}$ in Koreans, ${ }^{[9]}$ and 71.5 mm Germans. ${ }^{[21]}$ This shows a significant difference between measurements of these studies and the current study in an Iranian population; however, it can be noted that distal femur parameters in Iranian population were closer to German and Chinese populations.

Intercondylar notch is an anatomic site of interest as it lodges the anterior cruciate ligament. The morphology of the intercondylar notch may be clinically relevant to anterior cruciate ligament pathologies. NWI is also an important parameter to estimate knee prosthesis measurements. ${ }^{[22]}$ It is associated with damage to knee ligaments and is a useful parameter in knee arthroplasty and prostheses. So measurements of this variable is very important. ${ }^{[5,11,23,24]}$ In a recent CT study on an Iranian population, intercondylar notch width was measured as $20.39 \pm 3.4 \mathrm{~mm}, 21.76$ in males and $17.96 \mathrm{~mm}$ in females. ${ }^{[1]}$ These results are similar to our findings of NW in bony and MRI specimens.

The average NWI in this study was $0.29 \mathrm{~mm}$. This is slightly higher than the average NWI in previously published papers. Souryal et al. ${ }^{[17]}$ calculated NWI as 0.23 , Anderson et al. ${ }^{[25]} 0.26$, and results of the study by Chandrashekar et al. ${ }^{[26]}$ was the closest to the current study as 0.29 . This shows that there is a wide range in both intercondylar notch width and bicondylar width measurements, possibly due to the different age, gender or population of the study groups.

Poilvache et al. ${ }^{[19]}$ measured TEA in 111 knees and found as $5.38^{\circ}$ in females and $4.41^{\circ}$ in males. In this study, in bony specimens, TEA was $7.38^{\circ}\left(7.4^{\circ}\right.$ in males and $7.1^{\circ}$ in females) and in MRI images $6^{\circ}\left(6.4^{\circ}\right.$ in males and $5.7^{\circ}$ in females). This value is higher than reported in the previous studies.

\section{Conclusion}

The findings of this study on distal femur morphometry will be useful for the design and construction of knee prostheses for the Iranian population, and also be useful for clinicians involved in the TKA.

\section{References}

1. Chaichankul CA, Tanavalee M, Itiravivong P. Anthropometric measurements of knee joints in Thai population: correlation to the sizing of current knee prostheses. Knee 2011;18:5-10.

2. Yue B, Varadarajan KM, Ai S, Tang T, Rubash HE, Li G. Differences of knee anthropometry between Chinese and white men and women. J Arthroplasty 2011;26:124-30.

3. Vaidya SV, Ranawat CS, Aroojis MA, Laud NS. Anthropometric measurements to design total knee prostheses for the Indian population. J Arthroplasty 2000;15:79-85.

4. Dienst M, Schneider G, Altmeyer K, Voelkering K, Georg T, Kramann B, Kohn D. Correlation of intercondylar notch cross sections to the ACL size: a high resolution MR tomographic in vivo analysis. Arch Orthop Trauma Surg 2007;127:253-60.

5. Ireland ML, Ballantyne BT, LittlE K, MCClay IS. A radiographic analysis of the relationship between the size and shape of the intercondylar notch and anterior cruciate ligament injury. Knee Surg Sports Traumatol Arthrosc 2001;9:200-5.

6. Singh JA, Inacio MC, Namba RS, Paxton EW. Rheumatoid arthritis is associated with higher ninety-day hospital readmission rates compared to osteoarthritis after hip or knee arthroplasty: a cohort study. Arthritis Care Res 2015;67:718-24.

7. Uehara K, Kadoya Y, Kabayashi A, Ohashi H, Yamano Y. Anthropometry of the proximal tibia to design a total knee prosthesis for the Japanese population. J Arthroplasty 2002;17:102832 .

8. Kwak DS, Surendran S, Pengatteeri YH, Park SE, Choi KN, Gopinattan P, Han SH, Han CW. Morphometry of the proximal tibia to design the tibial component of total knee arthroplasty for the Korean population. Knee 2007;14:295-300.

9. Kwak DS, Han S, Han CW, Han SH. Resected femoral anthropometry for design of the femoral component of the total knee prosthesis in a Korean population. Anat Cell Biol 2010;43:252-9.

10. Rashidvash V. Anthropological and genetic characteristics of Atropatene population. Int J Humanit Soc Sci 2012;2:139-47.

11. Moghtadaei M, Moghimi J, Shahhoseini G. Distal femur morphology of iranian population and correlation with current prostheses. Iran Red Crescent Med J 2016;18(2):e21818.

12. Khodair SA, Ghieda UE, Elsayed AS. Relationship of distal femoral morphometrics with anterior cruciate ligament injury using MRI. Tanta Medical Journal 2014;42:64-68.

13. Reinhard KJ, Welner M, Okoye MI, Marotta M, Plank G, Anderson B, Mastellon T. Applying forensic anthropological data in homicide investigation to the depravity standard. J Forensic Leg Med 2013;20: $27-39$.

14. ScottJB, Gill GW, Kieffer DA. Race and sex determination from the intercodular notch of the distal femur. In: Gill GW, Rhine S, editors. Skeletal attribution of race. Albuquerque (NM): Maxwell Museum of Anthropology, University of New Mexico; 1990. pp. 83-90.

15. Johnston TB, Whillis J. Gray's anatomy. Descriptive and applied. 31st ed. London: Longmans Green and Co; 1954.

16. Al-Saeed O, Brown M, Athyal R, Sheikh M. Association of femoral intercondylar notch morphology, width index and the risk of anterior cruciate ligament injury. Knee Surg Sports Traumatol Arthrosc 2013;21:678-82. 
17. Souryal TO, Freeman TR. Intercondylar notch size and anterior cruciate ligament injuries in athletes. A prospective study. Am J Sports Med 1993;21:535-9.

18. Domzalski M, Grzelak P, Gabos P. Risk factors for anterior cruciate ligament injury in skeletally immature patients: analysis of intercondylar notch width using magnetic resonance imaging. Int Orthop 2010;34:703-7.

19. Poilvache PL, Insall JN, Scuderi GR, Font-Rodriguez DE. Rotational landmarks and sizing of the distal femur in total knee arthroplasty. Clin Orthop Relat Res 1996;(331):35-46.

20. Cheng FB, Ji XF, Lai Y, Feng JC, Zheng WX, Sun YF, Fu YW, Li YQ. Three dimensional morphometry of the knee to design the total knee arthroplasty for Chinese population. Knee 2009;16:3417.

21. Dargel J, Micheal JW, Feiser J, Ivo R, Koebke J. Human knee joint anatomy revisited: morphometry in the light of sex-specific total knee arthroplasty. J Arthroplasty 2011;26:346-53.
22. Ameet KJ, Murlimanju BV. A morphometric analysis of intercondylar notch of femur with emphasis on its clinical implications. Medicine and Health 2014;9:103-8.

23. Yue B, Varadarajan KM, Ai S, Tang T, Rubash HE, Li G. Gender differences in the knees of Chinese population. Knee Surg Sports Traumatol Arthrosc 2011;19:80-8.

24. Tillman MD, Smith KR, Bauer JA, Cauraugh JH, Falsettl AB, Pattishall JL. Differences in three intercondylar notch geometry indices between males and females: a cadaver study. Knee 2002;9:41-6.

25. Anderson AF, Anderson CN, Gorman TM, Cross MB, Spindler KP. Radiographic measurements of the intercondylar notch: are they accurate? Arthroscopy 2007;23:261-8.

26. Chandrashekar N, Slauterbeck J, Hashemi J. Sex-based differences in the anthropometric characteristics of the anterior cruciate ligament and its relation to intercondylar notch geometry a cadaveric study. Am J Sports Med 2005;33:1492-8.

Correspondence to: Tayebeh Rastegar, PhD

Department of Anatomy, School of Medicine,

Tehran University of Medical Sciences, Tehran, Iran

Phone: +98 2164053404

e-mail: trastegar@sina.tums.ac.ir

Conflict of interest statement: No conflicts declared.

This is an open access article distributed under the terms of the Creative Commons Attribution-NonCommercial-NoDerivs 3.0 Unported (CC BY-NCND3.0) Licence (http://creativecommons.org/licenses/by-nc-nd/3.0/) which permits unrestricted noncommercial use, distribution, and reproduction in any medium, provided the original work is properly cited. Please cite this article as: Shahsavaripour S, Barbarestani M, Hassanzadeh G, Rastegar T. Correlation between the femoral trochlear line - epicondylar line angle and intercondylar notch width index in an Iranian population. Anatomy 2017;11(2):87-92. 